\title{
Long Term Outcomes of Freestyle Stentless Aortic Bioprosthesis: A Single Center Experience
}

\author{
Mehmet Ezelsoy, ${ }^{1}$ Kerem Oral, ${ }^{1}$ Kemal Tolga Saracoglu, ${ }^{2}$ Ayten Saracoglu, ${ }^{3}$ Zehra Bayramoglu, ${ }^{1}$ \\ Belhhan Akpinar ${ }^{4}$ \\ ${ }^{1}$ Department of Cardiovascular Surgery, Istanbul Bilim University, Istanbul, Turkey; ${ }^{2}$ Department of Anesthesiology and Reanimation, \\ Health Sciences University, Istanbul, Turkey; ${ }^{3}$ Department of Anesthesiology and Reanimation, Istanbul Marmara University, Istanbul, \\ Turkey; ${ }^{4}$ Department of Cardiovascular Surgery, Istanbul Florence Nightingale Hospital, Istanbul, Turkey
}

\section{ABSTRACT}

Background: The study is presenting our long-term clinical results after freestyle stentless aortic root bioprosthesis replacement in patients with severe aortic insufficiency with ascending aortic aneurysm.

Methods: Seventy-seven patients with ascending aortic aneurysms and aortic valve insufficiency underwent a total root replacement procedure using a stentless "Freestyle" valve (Medtronic Inc., Minneapolis, Minnesota). There were $50(64.9 \%)$ men and $27(35.1 \%)$ women. Mean age was 68.7 \pm 11.1 years. The surgical procedure used a complete root replacement. Concomitant procedures included coronary artery bypass grafting in 15 (19.5\%) patients.

Results: The mean cardiopulmonary bypass time was $130.3 \pm 26.4$ minutes and total aortic cross clamp time was $99.5 \pm 23.6$ minutes. Hospital mortality was $2.6 \%$. The median follow-up time was 11.2 years. The 5 - and 10 -years freedom from aortic valve reoperation were $97.4 \pm 1.2 \%$ and $93.4 \pm 4.9 \%$, respectively. During 10 years follow up, there were 14 late deaths; 4 deaths were cardiac, and 10 deaths were noncardiac. Valve-related deaths were attributable to thromboembolism in 1 patient, endocarditis in 2 patients, and congestive heart failure in 1 patient.

Conclusion: The freestyle stentless aortic root bioprosthesis offered good clinical outcomes, in terms of survival and structural valve deterioration. The Freestyle valve is a viable option for use in patients undergoing bioprosthetic aortic valve replacement and expected desire for long-term durability.

\section{INTRODUCTION}

In ascending aortic aneurysm surgery with aortic valve insufficiency, the choice of operation must take into account lifestyle and predicted lifespan of the patient. The ideal valve choice includes acceptable operative mortality, identical

Received fuly 8, 2019; accepted September 10, 2019.

Correspondence: Mebmet Ezelsoy, Istanbul Bilim University, Cardiovascular Surgery Department, Sisli Florence Nightingale Hospital No: 164, Cardiovascular Surgery Department, Sisli, Istanbul, Turkey; 02122244950 (e-mail:mehmet_ezelsoy@hotmail.com). haemodynamics to a normal aortic valve, and no indication for long-term therapeutic anticoagulation.

Many studies have documented the durability of mechanical composite grafts for aortic root replacement, the Bentall procedure with its many modifications as a safe and reproducible surgical procedure [Kouchoukos 1991; Bentall 1968]. However, this surgical strategy requires life-long anticoagulation, often not well accepted or tolerated by patients [Mastrobuoni 2016].

Biological prosthesis such as homografts, pulmonary autografts, and stentless bioprosthesis (porcine root or stentless pericardial valve) have gained more attention because they can minimize the risk of thromboembolism and anticoagulationrelated problems.

In this report, we assessed the long-term outcomes of patients who received aortic root replacement with freestyle stentless aortic root bioprosthesis.

\section{MATERIALS AND METHODS}

Data collection: All patient preoperative demographic and clinical data were collected, including age at operation, gender, indication for aortic valve/root surgery, major comorbidities, and New York Heart Association Heart Failure Class (NYHA). Operative data included concomitant cardiac or aortic interventions and implanted valve size. Total root replacement was performed for all patients. The study was performed in accordance with the Helsinki Declaration and approved by the Ethics Committee of Istanbul Demiroglu Bilim University. In addition, written informed consent was obtained from all study patients.

Study population: Patient baseline and operative information retrospectively were collected. We identified 77 consecutive patients with ascending aortic aneurysm (AAA) and aortic valve insufficiency, who underwent total root replacement with the Freestyle valve between January 2003 and December 2008. Selection criteria for this method were age greater than 65 years, contraindication to oral anticoagulants, and deliberate request for a biological valve by the patient. Redo operations were excluded from this study. During this period, 85 patients and 147 patients, who were not eligible for Freestyle valve underwent aortic root replacement with a mechanical valve and aortic valve replacement with supracoranary 
Table 1. Patient Demographics and Comorbidities

\begin{tabular}{lc}
\hline & $\mathrm{N}(\%)$ \\
\hline Gender & \\
$\quad$ Female & $27(35.1 \%)$ \\
Male & $50(64.9 \%)$ \\
Age (years) & $68.7 \pm 11.1$ \\
NYHA I-II & $33(42.8 \%)$ \\
NYHA III-IV & $44(57.1 \%)$ \\
BMI & $26.8 \pm 2.0$ \\
Ejection fraction (\%) & $54.2 \pm 5.0$ \\
LVESVI(mL/m $\left.{ }^{2}\right)$ & $47.7 \pm 27.6$ \\
LVEDVI $\left(\mathrm{mL} / \mathrm{m}^{2}\right)$ & $58.1 \pm 8.7$ \\
Bicuspid aorta & $15(19.4 \%)$ \\
Comorbidities & \\
COPD & $19(24.7 \%)$ \\
CRF & $4(5.2 \%)$ \\
HT & $26(33.8 \%)$ \\
DM & $22(28.6 \%)$ \\
HL & $21(27.3 \%)$ \\
PVD & $9(11.7 \%)$ \\
\hline
\end{tabular}

NYHA: New York Heart Association, BMI: Body Mass Index, LVESVI: Left Ventricular End-Systolic Volume Index, LVEDVI: Left Ventricular EndDiastolic Volume Index, COPD: Chronic Obstructive Pulmonary Disease, CRF: Chronic Renal Failure, HT: Hypertension, DM: Diabetes Mellitus, HL: Hyperlipidemia, PVD: Peripherial Vascular Disease.

graft interposition, respectively. The selection of implantation technique was based on patient anatomy, cause of aortic valve disease, and surgeon discretion. Clinical follow-up was completed with all patients. Transthoracic echocardiograms were obtained every year to measure left ventricular ejection fraction, transvalvular aortic pressure gradients, presence and severe aortic insufficiency (AI), and structural valve deterioration (SVD). Structural valve deterioration includes permanent intrinsic changes of the valve (i.e. leaflet tear, calcification, pannus deposition, flail, or fibrotic leaflet) leading to degeneration and/or dysfunction, which in turn may result in stenosis or intra-prosthetic regurgitation.

Surgical technique: The right femoral artery was exposed and cannulated for arterial return in 65 patients. In 12 patients with severe atherosclerotic disease of the femoral vessels, the right axillary artery was prepared. An $8 \mathrm{~mm}$ Goretex graft was anastomosed to the axillary artery, and the arterial cannula was introduced through the graft. In all cases cardiopulmonary bypass $(\mathrm{CPB})$ was established with a two-stage venous cannula in the right atrium, and the left ventricle was vented via the right superior pulmonary vein. While the patient was cooled down to $28^{\circ} \mathrm{C}$, the aorta was clamped and tepid blood cardioplegia administered. Retrograde blood cardioplegia
Table 2. Surgical Characteristics, Postoperative Complication, and Mortality Rate

\begin{tabular}{lc}
\hline Aneurysm diameter (cm) (mean) & $5.7 \pm 0.8$ \\
CPB time (min) & $130.3 \pm 26.4$ \\
CX time (min) & $99.5 \pm 23.6$ \\
TCA (min) & $24.9 \pm 5.5$ \\
ICU stay (day) & $1.9 \pm 0.8$ \\
Hospital stay (day) & $8.3 \pm 1.5$ \\
Prosthesis size $19(\mathrm{~N})$ & $3(3.9 \%)$ \\
Prosthesis size $21(\mathrm{~N})$ & $5(6.5 \%)$ \\
Prosthesis size $23(\mathrm{~N})$ & $11(14.3 \%)$ \\
Prosthesis size $25(\mathrm{~N})$ & $26(33.8 \%)$ \\
Prosthesis size $27(\mathrm{~N})$ & $21(27.3 \%)$ \\
Prosthesis size $29(\mathrm{~N})$ & $9(11.7 \%)$ \\
Concomittant CABG (N) & $15(19.5 \%)$ \\
Neurologic complication $(\mathrm{N})$ & $4(5.2 \%)$ \\
Pulmonary complication $(\mathrm{N})$ & $2(2.5 \%)$ \\
Infectious complication $(\mathrm{N})$ & $2(2.5 \%)$ \\
Bleeding (N) & $3(4.4 \%)$ \\
Hospital mortality $(\mathrm{N})$ & $2(2.5 \%)$ \\
\hline
\end{tabular}

CPB: cardiopulmonary bypass, Cx: cross clamp, TCA: total circulatory arrest, ICU: intensive care unit, CABG: coronary artery bypass graft

in combination with direct antegrade cardioplegia from the right coronary ostium was used for myocardial protection. The aorta was transected, and both coronary ostia were mobilized on generous buttons of aortic wall. The remaining tissue of the valsalva was excised, and the diseased aortic wall removed. While the Freestyle valve was being washed, we developed inflow sutures using 2-0 tycron sutures (Davis Geck, Danbury, Connecticut).

Then, we trimmed the porcine valve to create holes for the mobilized coronary ostia by removing excessive buttons of porcine aortic tissue from the left and right coronary sinuses indicated on the valve. A thin strip of pericardium was incorporated in the inflow suture line for hemostasis. Continuous 6-0 polypropylene sutures were used to reimplant each coronary ostium by means of its button of aortic wall in its corresponding sinus of valsalva. After the proximal anasthomosis of Freestyle graft, the distal part of Freestyle graft was established to the aorta. We used $319 \mathrm{~mm}, 521 \mathrm{~mm}, 1323 \mathrm{~mm}, 26$ $25 \mathrm{~mm}, 2127 \mathrm{~mm}$, and $929 \mathrm{~mm}$ Freestyle valves. De-airing was performed, using standard methods under transesophageal echocardiography (TEE) monitoring.

Stentless aortic valve reoperation: Our current strategy for managing reoperation includes: (1) aortic valve replacement (AVR) as valve-in-valve: If the initial Freestyle porcine aortic root annulus is not calcified with a good valve size $(\geq 23 \mathrm{~mm}$ valve), we decided to perform a new stented valve or mechanical valve in the stentless root as valve-in-valve; (2) AVR with 
Table 3. Echocardiographic Results

LVESVI: Left ventricular end-systolic volume index, LVEDVI: Left ventricular end-diastolic volume index

or without aortic root repair after removing the previous stentless valve: The Freestyle porcine aortic root is explanted if heavy calcification of the porcine aortic root is encountered or if the Freestyle porcine aortic root cannot hold an adequate-sized prosthesis as valve-in-valve.

Statistical analysis: Data are expressed as mean \pm SD or median (range) for continuous variables and as number (percentage) for categorical variables. All statistical analyses were performed using SPSS 21.0. Statistical analyses were performed using univariate statistical methods (paired samples t-test) and Kaplan-Meier survival curve. $P<.05$ was considered as statistically significant.

\section{RESULTS}

There were 50 (64.9\%) men and 27 (35.1\%) women. Mean age was $68.7 \pm 11.1$ years. Mean preoperative ejection fraction was $54.2 \pm 5.0 \%$. Left ventricular end-systolic and end-diastolic volume indexes were $47.7 \pm 27.6 \mathrm{~mL} / \mathrm{m}^{2}$ and $58.1 \pm 8.7$ $\mathrm{mL} / \mathrm{m}^{2}$, respectively. Fifteen patients $(19.4 \%)$ had a diagnosis of bicuspid aorta preoperatively (Table 1 ).

Before the surgery, 33/77 (42.8\%) patients were in NYHA class I or II, whereas $44 / 77(57.1 \%)$ belonged to NYHA class III or IV.

The mean aneurysm diameter was $5.7 \pm 0.8 \mathrm{~cm}$. There were four patients with a chronic type A dissection. Concomitant procedures included coronary artery bypass grafting in $15(19.5 \%$ ) patients ( 9 of them were 2 grafts; 6 of them were 3 grafts used). One patient (1.2\%) was readmitted to the hospital with a deep sternal wound infection on postoperative day seven.

All patients were weaned from cardiopulmonary bypass with moderate inotropic support. The mean cardiopulmonary bypass time was $130.3 \pm 26.4$ minutes, and total aortic crossclamp time was $99.5 \pm 23.6$ minutes. Mean total circulatory arrest time was $24.9 \pm 5.5$ minutes. Transient ischemic attack was observed in 4 patients (5.2\%) during hospital stay, and 2 patients $(2.5 \%)$ were treated with antibiotics for superficial wound infection. Two patients $(2.5 \%)$ had pulmonary complications with moderate pleural effusion. Hospital mortality was $2.5 \%(\mathrm{~N}=2)$ (Table 2$)$.

Three (4.4\%) patients were reoperated upon for bleeding that resolved before discharge. At discharge all patients had a competent valve with low transvalvular gradients $(9.2 \pm 4.5$ $\mathrm{mmHg}$ ). At 5 and 10 years follow up, mean aortic gradient was $9.1 \pm 3.8 \mathrm{mmHg}$ and $9.4 \pm 4.9 \mathrm{mmHg}$, respectively. At 5 years follow up, mean ejection fraction was $49.7 \pm 3.7 \%$ and at 10 years follow up, mean ejection fraction was $48.5 \pm 2.4 \%$ $(P<.05)$.

Left ventricular end-systolic and end-diastolic volume indexes significantly were reduced on 5 and 10 years follow-up

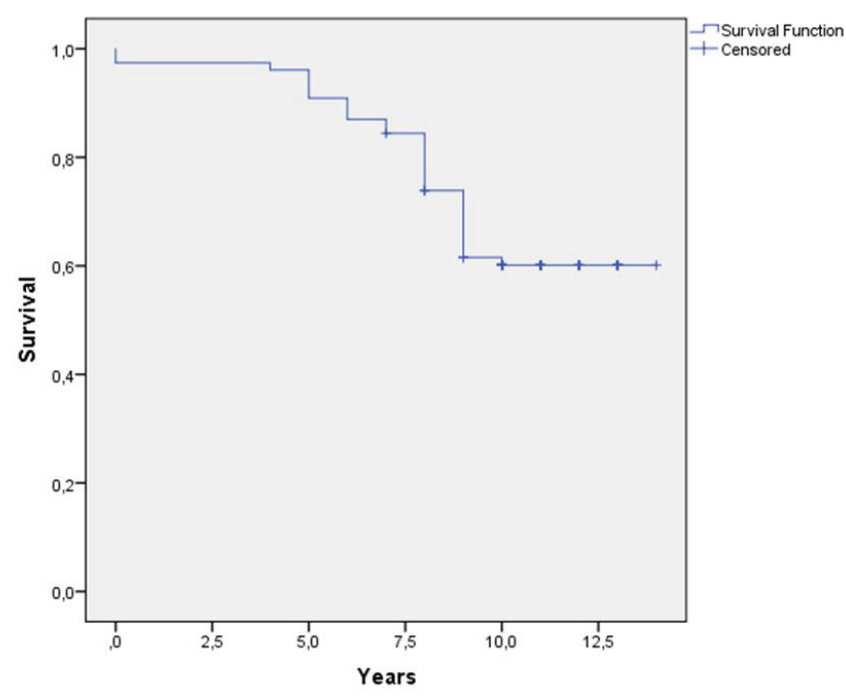

Kaplan-Meier curve shows overall actuarial survival

echocardiographic examination, in comparison with the discharged values $(45.8 \pm 35.5$ versus $39.24 \pm 28.7$ and $54.63 \pm$ 6.97 versus $52.42 \pm 4.55 \mathrm{~mL} / \mathrm{m}^{2}$, respectively; both $P<.05$ (Table 3).

There were a total of 4 late reoperations at 10 years follow up. Reoperations were attributable to structural valve deterioration (SVD) in 3 patients ( 2 stenosis; 1 regurgitation) and endocarditis in 1 patient. Valve in valve was applied to these 3 patients and reroot replacement was applied to the other patient. Reoperation rate of our clinic at 5 years was $2.5 \%(\mathrm{~N}$ $=2)$ and between 5 and 10 years was $3.9 \%(\mathrm{~N}=3)$. The 5 - and 10 -years freedom from aortic valve reoperation were $97.4 \pm$ $1.2 \%$ and $93.4 \pm 4.9 \%$, respectively.

During 10 years follow up, there were 14 late deaths; 4 were cardiac, and 10 were noncardiac. Cardiac deaths (5.1\%) were attributable to thromboembolism in 1 patient, endocarditis in 2 patients, and congestive heart failure in 1 patient. The median follow-up time was 11.2 years (Figure).

\section{DISCUSSION}

Ascending aorta and root replacement remained the gold standard for the surgical treatment of proximal aortic aneurysmal disease for the last 40 years. Alternative surgical procedures using bioprosthesis have been introduced over the years, such as cryopreserved homografts, pulmonary autografts, a bioprosthesis sewn into a prosthetic tube graft, and valve-sparing root reconstructions [David 2002].

The Medtronic Freestyle bioprosthesis (Medtronic Inc., Minneapolis, Minnesota, USA) is an intact porcine aortic root, which has shown excellent haemodynamic results as well as good long-term durability and low rate of valve-related morbidity [Ennker 2009]. The Freestyle aortic root bioprosthesis can be implanted by several surgical techniques: complete or modified subcoronary valve replacement, root inclusion, and full-root replacement [Ennker 2008]. 
Stentless porcine root grafts have distinct advantages over mechanical composite grafts, including superior valve hemodynamic performance, rapid regression of left ventricular hypertrophy, and the avoidance of anticoagulation, theoretically resulting in an improved event-free survival [Doty 1998; Gulbins 2009].

Bach et al [Bach 2005] showed excellent durability and hemodynamic profile for the Freestyle root graft in a multicenter experience with 178 patients (mean age, 60 years). After 10 years of follow up, freedom from structural valve deterioration was $92 \%$, freedom from reoperation was $92.3 \%$, and mean valve gradients were $7.0 \pm 4.1 \mathrm{~mm} \mathrm{Hg}$. In our study, reoperation for structural valve deterioration at the first 5 years was $1.3 \%(\mathrm{~N}=1)$ and at the 5 to 10 years follow up was $2.6 \%(\mathrm{~N}=2)$.

In our experience, the major advantage of the Freestyle valve is its versatility. It can be used as a whole root or a subcoronary implantation can be performed during ordinary AVR [Silberman 2001]. An account of a root inclusion procedure with this valve for the treatment of an acutely dissected root in an elderly patient was published by Westaby [Westaby 1998]. Excellent early- and mid-term results (7 years) had made this valve a choice for patients undergoing AVR who are over 65 years of age [Cartier 1999]. This valve was an appealing option for our patients in this series because most of them were elderly.

Replacement of the aortic valve with a stentless xenograft is a more demanding surgical procedure, and attention to detail is essential. Hemorrhage, the most common problem in this surgery, can be prevented with some minor precautions. First, taking deep sutures from the annulus and incorporating a strip of pericardium between the Freestyle valve and annulus is very helpful for hemostasis. Secondly, the coronary ostia must be removed completely and the corresponding openings on the Freestyle valve must be generous in order to prevent tension. We advise the enlargement of the openings on the Freestyle valve to prevent any kinking of the coronary ostia and to permit a tension-free anastomosis. Finally, the length of the tube graft must be correctly measured. A graft that is too short will cause tension on the anastomosis and may lead to bleeding and dehiscence. On the other hand, a graft that is too long may cause kinking, but this can be resolved with external traction sutures outside the graft. The major drawback of the method is the need for a second tube graft to reach the distal arch because the Freestyle valve is not long enough.

We extended the Freestyle graft by adding a Dacron graft to the distal part of the aorta and sutured the Freestyle graft to the Dacron graft. This additional procedure requires a short time of total circulatory arrest and prolongs the ischemic time. However, with good myocardial protection, which can be achived with retrograde cardioplegia, this is of minor importance. Another criticism of the method may be the difficulty of a future reoperation caused by porcine aortic wall calcification. In our study group, we performed 4 reoperations. Most of them were due to SVD. In these patients, we experienced that the calcification of the porcine aortic graft wall was minimal and it did not affect to our operational strategy.
Large studies of prosthetic aortic root replacements have reported a range of short-term mortality of $0.7 \%$ to $12 \%$ and long-term survival of $75 \%$ at 5 years to $91 \%$ at 16 years [Schachner 2005; Gelsomino 2003]. The wide range reported in these studies is partially explained by their inclusion of higher-risk patients such as urgent or emergency operations, dissections, endocarditis, redo sternotomies, previous AVR, specific genetic conditions, or older patients [Karangelis 2018]. When limited to elective operations only, mortality rates of the present study are comparable to other studies [Woldendorp 2014]. This study also represents findings from a more recent era and may reflect some general improvement in surgical and intensive care unit outcomes [Shapira 1999]. Lastly, this study demonstrates the excellent durability of prosthetic aortic root replacements, with a 10 -year freedom of reoperation greater than $93 \%$.

For the moment, we agree with others who have suggested that the general guidelines for the use of other bioprosthesis should be applied to these valves until multicenter and randomized longer-term results are available. Although only the test of time, as reflected in our results over 10 years after implantation, will prove the value of these valves, the results so far are encouraging.

The results from this study potentially serve as a benchmark of comparison for the different operative strategies in the treatment of AI, with or without aneurysmal disease, particularly in young patients undergoing elective operations. As aortic valve repair techniques continue to evolve and to ideally undergo a greater degree of dissemination to promote improved patient access, better understanding the outcomes of prosthetic aortic root replacements in patients with clinically significant AI is important. The prosthetic aortic root replacement operation is less dependent on surgeon experience and remains the most reproducible and widely available operation for concomitant aortic valve and ascending aortic disease, with excellent results both in this study and others [Hagl 2003].

Transcatheter aortic valve replacements (TAVI) increasingly are utilized for patients considered non-operative candidates for reoperative AVR. TAVI now is the recommended therapy in elderly patients with aortic stenosis who are inoperable or at increased surgical risk [Vahanian]. We believe that, sutureless valve-instentless root could be another option for reoperative AVR as valve-in-valve which would decrease the need for redo root replacement in a heavily calcified degenerative stentless valve.

\section{STUDY LIMITATIONS}

The number of patients reaching 10 years of follow up is few. Long-term data was collected retrospectively and may similarly underestimate the number of total adverse events. Although not the aim of the current study, the comparison of the long-term outcomes of patients receiving the FSB with those receiving other aortic valve prostheses at our institutions would additionally be beneficial. 


\section{CONCLUSION}

Our results compare favorably with those of other biological valve studies. The Freestyle bioprosthesis provides good long-term clinical and echocardiographic outcomes and showed encouraging durability up to 10 years with low rates of valve-related morbidity.

\section{REFERENCES}

Bach DS, Kon ND, Dumesnil JG, Sintek CF, Doty DB. 2005. Ten-year outcome after aortic valve replacement with the Freestyle Stentless Bioprosthesis. Ann Thorac Surg 80:480-7.

Bentall H, De Bono A. 1968. A technique for complete replacement of the ascending aorta. Thorax 23:338 -9.

Cartier CP, Dumensil GJ, Metras J, Desaulniers D, Doyle DP, Lemieux MD, et al. 1999. Clinical and hemodynamic performance of the Freestyle aortic root bioprosthesis. Ann Thorac Surg 67:345-51.

David TE, Ivanov J, Armstrong S, Feindel CM, Webb GD. 2002. Aortic valve-sparing operations in patients with aneurysms of the aortic root or ascending aorta. Ann Thorac Surg 74:1758-61.

Doty DB, Cafferty A, Kon ND, Huysmans HA, Krause AH Jr, Westaby S. 1998. Medtronic Freestyle aortic root bioprosthesis: implant techniques. J Card Surg 13:369-75.

Ennker JAC, Albert AA, Rosendahl UP, Ennker IC, Dalladaku F, Florath I. 2008. Ten-year experience with stentless aortic valves: full-root versus subcoronary implantation. Ann Thorac Surg 85:445-53.

Ennker JAC, Ennker IC, Albert AA, Resendahl UP, Bauer S, Florath I. 2009. The Freestyle stentless bioprosthesis in more than 1000 patients: a single-center experience over 10 years. J Card Surg 24:41-8.

Gelsomino S, Morocutti G, Frassani R, Masullo G, Da Col P, Spedicato L, et al. 2003. Long-term results of Bentall composite aortic root replacement for ascending aortic aneurysms and dissections. Chest 124:984-8.

Gulbins H, Reichenspurner H. 2009. Which Patients Benefit From Stentless Aortic Valve Replacement? Ann Thorac Surg. 88(6):2061-8.
Hagl C, Strauch JT, Spielvogel D, Galla JD, Lansman SL, Squitieri R, et al. 2003. Is the Bentall procedure for ascending aorta or aortic valve replacement the best approach for long-term event-free survival Ann Thorac Surg 76:698-703.

Karangelis D, Tzertzemelis D, Demis AA1, Economidou S, Panagiotou M. 2018. Eighteen years of clinical experience with a modification of the Bentall button technique for total root replacement. J Thorac Dis. 10 (12):6733-6741

Kouchoukos NT, Wareing TH, Murphy SF, Perrillo JB. 1991. Sixteenyear experience with aortic root replacement. Results of 172 operations. Ann Surg 214:308 -20.

Mastrobuoni S, de Kerchove L, Solari S, Astarci P, Poncelet A, Noirhomme P, Rubay J, El Khoury G. 2016. The Ross procedure in young adults: over 20 years of experience in our Institution. Eur J Cardiothorac Surg. 49(2):507-12; discussion 512-3.

Schachner T, Vertacnik K, Nagiller J, Laufer G. 2005. Factors associated with mortality and long time survival in patients undergoing modified Bentall operations. J Cardiovasc Surg 46:449-55.

Shapira OM, Aldea GS, Cutter SM, Fitzgerald CA, Lazar AN, Shemin RJ. 1999. Improved clinical outcomes after operation of the proximal aorta: a 10-year experience. Ann Thorac Surg 4:1030-7.

Silberman S, Shaheen J, Merin O, Fink D, Shapira N, Liviatan-Strauss N, Bitran D. 2001. Exercise hemodynamics of aortic prostheses: comparison between stentless bioprostheses and mechanical valves. Ann Thorac Surg. 72(4):1217-21.

Vahanian A, Alfieri O, Andreotti F, Antunes MJ, Baron-Esquivias G, Baumgartner H, Borger MA, Carrel TP, De Bonis M, Evangelista A, Falk V, Iung B, Lancellotti P, Pierard L, Price S, Schafers HJ, Schuler G, Stepinska J, Swedberg K, Takkenberg J, Von Oppell UO, Windecker S, Zamorano JL, Zembala M. Guidelines on the management.

Westaby S, Katsumata T, Houel R, Shinfeld A. 1998. Stentless xenograft repair of the dissected aortic root. Ann Thorac Surg 65:1448-50.

Woldendorp K, Starra E, Seco M, Hendel PN, Jeremy RW, Wilson MK, et al. 2014. Replacement of the aortic root with a composite valve-graft conduit: risk factor analysis in 246 consecutive patients. Heart Lung Circ 23:1187-93. 